\title{
ANALYSIS ON 3D RECONSTRUCTION OF THE MONUMENT TO HEROES AS A TOOL FOR A CONCEPTUAL AND METHODOLOGICAL APPROACH IN THE PATRIMONIZATION AND EVALUATION OF CULTURAL INTEREST GOODS.
}

\author{
M.I.Rodriguez-Laiton ${ }^{1 *}$, H.A.León-Vega ${ }^{2}$, E.Upegui ${ }^{3}$. \\ ${ }^{1}$ Cadastral and Geodesy Engineering, hotbed of research, GRSS-IEEE UD Group, Universidad Distrital Francisco José de Caldas, \\ Bogotá D.C, Colombia - mirodriguezl@ correo.udistrital.edu.co \\ ${ }^{2}$ Cadastral and Geodesy Engineering, hotbed of research PENSANTE (Pensamiento Espacial y Territorial) Spatial and Territorial \\ Thinking, Universidad Distrital Francisco José de Caldas, Bogotá D.C, Colombia - haleonv@ @orreo.udistrital.edu.co \\ ${ }^{3}$ Universidad Distrital Francisco José de Caldas, Faculty of Engineering, GEFEM and GRSS-IEEE UD Groups, Bogotá, Colombia \\ esupeguic@ correo.udistrital.edu.co
}

\section{Commission II}

KEY WORDS: SFM Photogrammetry, 3D Modeling, Point Cloud, Camera Calibration, Triangle Mesh. Cultural heritage, Dimension.

\begin{abstract}
:
The following article describes the implementation of a methodology for the structural reconstruction of the Heroes monument and the statue on the north side of Simon Bolivar Ecuestre located between the intersection of the north highway and 80th Street in Bogota (Colombia) from the acquisition of SFM photogrammetry methods and images, using low-cost sensors for this process and making use of drones from the obtaining of frames of a video to for areas with lower altimetric reach, and thereby creating an analysis in their accuracy, sizing and quality within the framework of appropriation and documentation of the cultural assets in the public space of the city Bogotá taking this data as a starting point for future developments in the process of 3D reconstructions Colombia.
\end{abstract}

\section{INTRODUCTION}

The evaluation of Cultural Interest Assets is a topic addressed by different disciplines, especially the Arts and Architecture, however, they currently use different methods to meet the demand for information, documentation, management and dissemination have had deficiencies in the implementation of new technologies to generate an analysis of these elements. (Gutierrez Gómez, 2018)

Despite this, the evolution of these technologies has been created that, based on the similarity of images and computer vision tasks, create a new form of recognition, categorization and classification of textures of objects, taking as a starting point the SIFT approach to extracting (key) points of interest from images while objects are in disarray, with different scale, and without requiring preprocessing for the algorithm application. (Strecha et al., 2015)

\section{HERITAGE}

During the latter, within the framework of local development approaches, new views on architectural heritage and its territorial referencing are taking place, as a key role in strengthening new identities and also in creating new spaces for development in the sector. (Vinuesa, 1998)

In this sense, heritage has had a very representative focus on its historical integrity, promoting personal development through knowledge and as a vehicle for social integration, thereby defining this concept as a symbol of promoting your own image outwards or as a dynamic almatic economic resource for the country. (Garai-Olaun, s. f.)

\subsection{NORMATIVE LAWS}

The national legislation in Colombia reflects through its articles $70,71,72$ of the national constitution the concept of heritage as a cultural good that makes up the national identity is therefore inalienable ununderstandable and imprescriptible this is an incentive to promote and promote access to culture and in turn for new creations.

Through Law 397 of 1997 governs and promotes the implementation of the Heritage of the Nation as a product of material goods of Colombian nationality of a furniture and property especially of interest historical, scientific, aesthetic or symbolic in architectural, urban and testimonial fields and from Decree 763 of 2009 establishes its state entities that at the national and territorial level that developsran,finance,encourageor executeactivities related tothe cultural heritage of the nation.

And with Decree 070 of 2015 the District System of Cultural Heritage is declared as a principal identity in the contribution to valuation, preservation, among others for disclosure and appropriation Bogota, D.C. heritage.

Finally, With Resolution 0395 of 200 6, the Monument to Heroes is declared a Good of National Cultural Interest in the categories of real estate located in the Colombian territory.

\subsection{PHOTOGRAMMMETRY SFM}

The Structure from Motion (SfM) technique is considered to be a high-resolution, low-cost automated photogrammetric method 
in relation to othertechniques. A method based on the same principles as classical stereoscopic photogrammetry, i.e. the 3D structure can be solved from an overlay of optical images obtained from different points of view. SfM has its origins in machine vision from the development of automatic image correlation algorithms (CAIs), a process by which it changes perspective on photogrammetry where the geometry of the scene, camera positions and orientation and deformations are solved by computational calculations. (Kumar, Muknahallipatna, \& McInroy, 2016)

For this reason, from this technique by the description of relevant characteristics of each image and their relationship between coincident or nearby points for each pair of shots independently at the scale of the and the technical aspects of the image itself such as brightness, color, contrast, etc. and a Bundler setting that will result in the more or less dense scattered point cloud depending on the number of common points between images eventually generating a set of XYZ coordinates, or cloud of dense spots.(Schneider, Schwalbe, \& Maas, 2009)

\subsection{CONSERVATION OF THE HERITAGE}

The possibility of obtaining three-dimensional models from images has opened up numerous possibilities in the field of heritage recovery. The high availability of images of cities and monuments where it is possible to be purchased on the internet, or from photographs captured to the taste of theirneed. These projects use such images in robust SfM systems to rebuild large monuments, or even entire cities with impressive results and resulting in a replica of a lot of monuments with incalculable historical and cultural value.

Therefore, thanks to the existence of photographic files taken, and the application of SfM techniques it is possible to "recover" a city or monument named World Heritage Site. (Abad Garcia, 2017)

\section{DESCRIPTION}

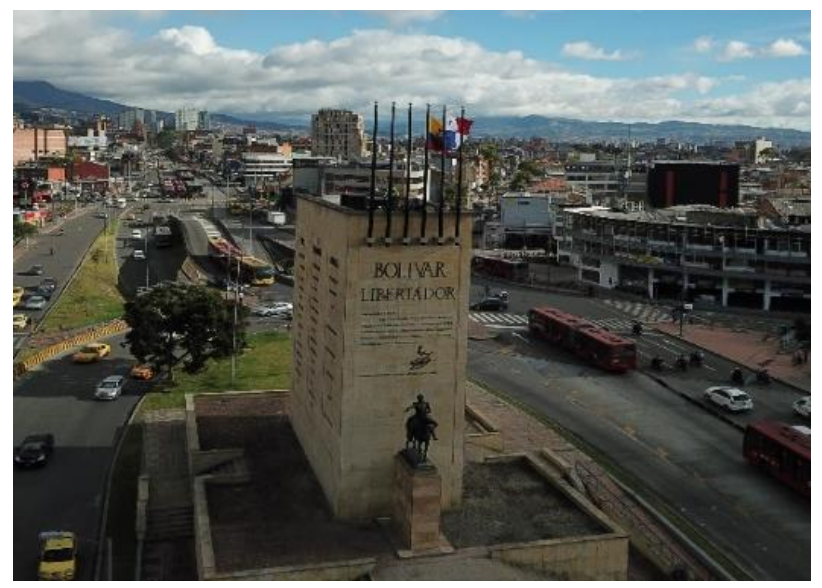

Figure 1: Monument to Heroes. IDPC source.

The monument to the heroes is a monument in Bogotá Colombia, which commemorates the wars of Independence, so that on the faces of the stone tower are inscribed data of the battles fought by the independent army in Colombia, Venezuela, Ecuador, Peru and Bolivia, consists of two elements such as the sculpture of the Equestrian Bolívar made by the French artist Emmanuel Frémiet and a 6-story structure that was built by the Italian Vico Consortium from which the names of six battles were observed that were fundamental for the Nueva Granada will get rid of the Spanish domain where the Battle of Boyacá, the Battle of Carabobo, the Battle of Bomboná, the Battle of Junín, the Battle of Pichincha and Battle of Ayacucho are evidenced in chronological order (Figure 1.). (Tiempo, 2016)

\section{MATERIALS AND METHODS}

\subsection{STUDY AREA}

For the development of the reconstruction, the reference data was acquired from the capture of images of the Monument to Heroes, located between the north highway and 80th Street in Bogotá a highly busy sector (Figure 2 ).

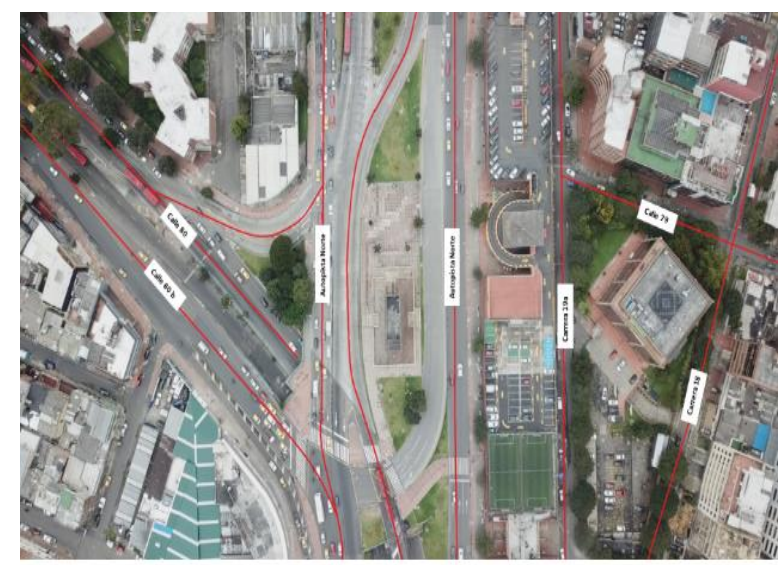

Figure 2: Location Of The Monument Of Heroes Using A Google Maps Image As A Base.

Own Source.

With this place you can analyze and give focus to inspect the sizing and quality of textures of the monument to heroes regarding the patrimonization of this, and the public space present; for its construction in limestone, a material that by its opaque tones highlights the mythical sculpture of Simón Bolívar thus creating several analyzes with respect to two totally different structures. (IDPC, 2016)

\subsection{SOFTWARE}

All results were generated by Pix4Dmapper Pro 2.0 which implements a fully automated workflow for the different parts of reconstruction from initial processing, camera calibration, point cloud densification display of the final result of the 3D reconstruction with the corresponding textured mesh. It should be noted that for this process it uses the Transformed SIFT responsible for identifying characteristics in each image that are invariants in scale, rotation and changes in lighting conditions, in this way, the points of interest, or 'key points', will be automatically identified at all scales and locations in each image.

These key points are reflected by highly differentiable details in each image, without the presence of movement or with too many coincidences in the color and shape of the element in the same image.

\subsection{CAMERA AND DRONE}

Taking into account that you want to use a low-cost instrument; you decide to use a Canon PowerShot SX400 and use data 
provided by the DISTRITAL CULTURAL PATRIMONY INSTITUTE (IDPC) of a drone flight using the Phanton 4 for the obtaining a video of the tour of the Monument to Heroes. (García, Calvache, Escarcena, \& Arenas, 2011) One very important thing to keep in mind is that the software identifies the type of camera with which the images were captured so that at the time of the process you have to select the camera correctly (Figure 3). (Barazzetti, Previtali, \& Roncoroni, 2017)

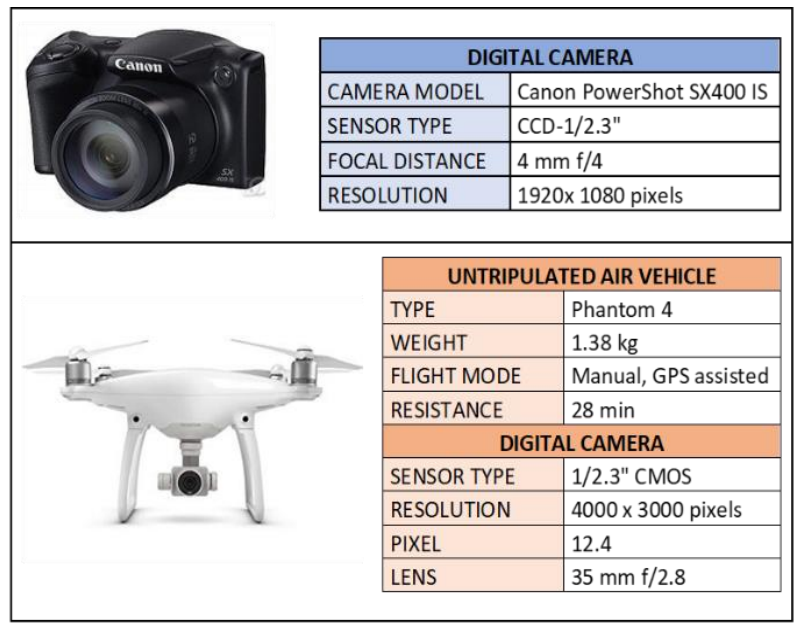

Figure 3: Main features of the camera and drone used. Own Source.

\subsection{MODELING:}

For the generation of the 3D model is based on different processes based on the use of the pix $4 \mathrm{D}$ starting from the acquisition of data from both the camera and drone and performing two techniques the initial processing and its generation of point cloud to obtain the finished product (Figure 4).

For this process, 175 .jpg format images were used in order from the use of the camera and 424 in various trajectories taking as a starting point the video generated by the drone making frames of this every half second of time (Figure 5). (Pérez, Gonçalves, Rangel, \& Ortega, 2019)

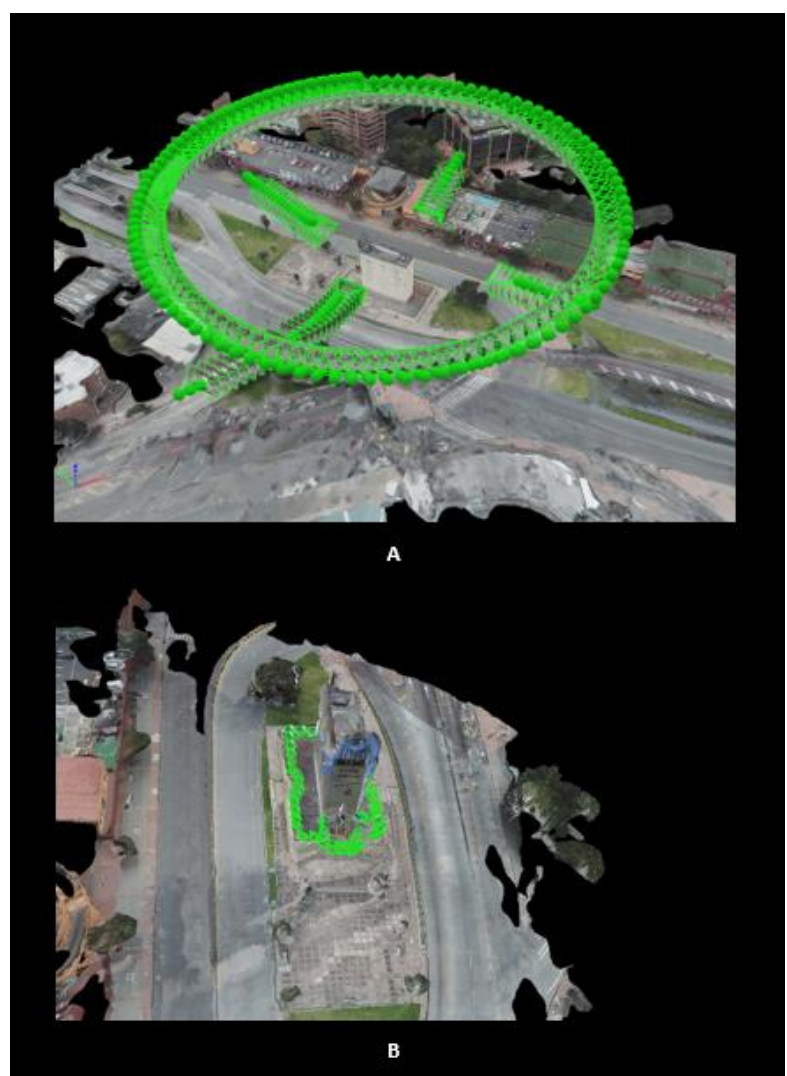

Figure 5: Distribution of Images of the Monument to Heroes from A) Canon Camera, B) Drone Flight Source: Own elaboration.

From this data four processing is generated for the analysis of such data which are part of the methodology proposed:

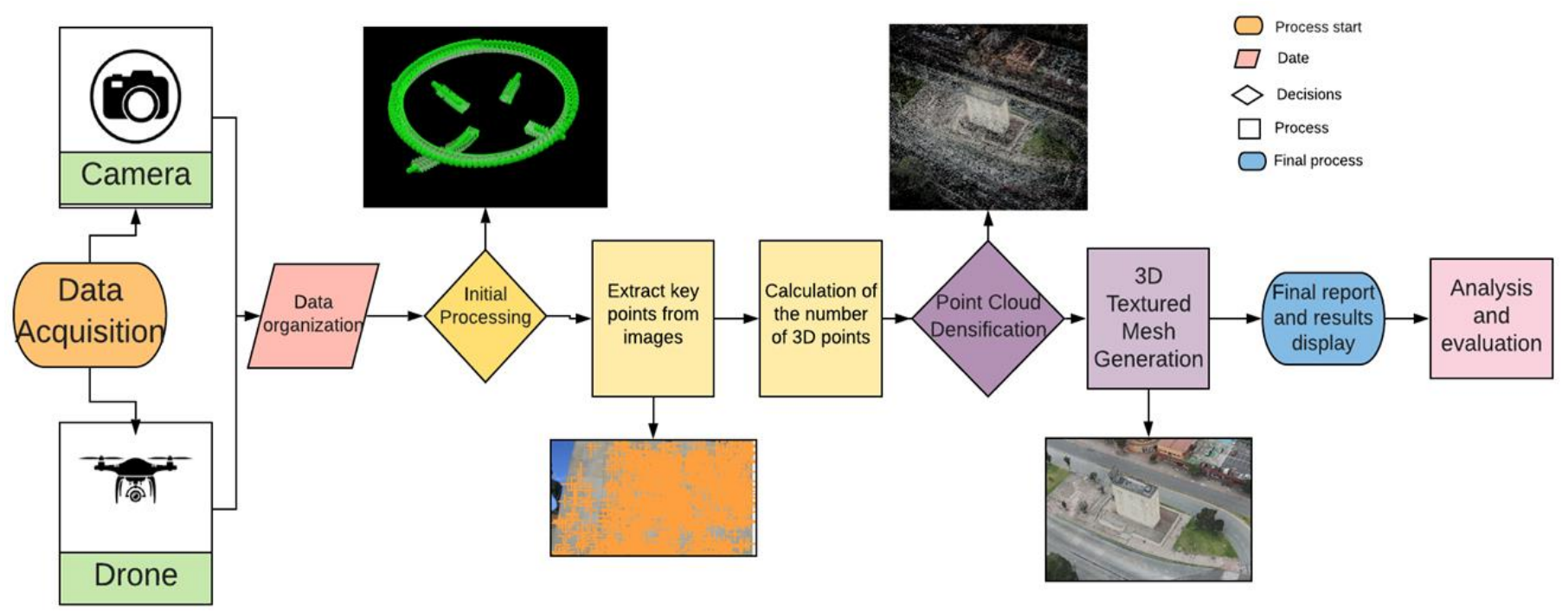

Figure 4: Processing flowchart.

Source: Own elaboration 
a) With the capture of data generated by the CANON camera from the point of view of the earth's surface (175 images).

b) With the frames generated by the drone tour $(424$ images).

c) With data from processes a) and b) from a single section of the drone flight (239 images).

d) Photographs taken from a cenit-nadir view of the statue of Simon Equestrian Bolivar (71 images).

With these images is defined from the large amount of matching of each image its calibration thus deserting in the process of all images inserted a) 1 image, b) 78 images, c) 1 image and d) there were no uncalibrated images (Figure 6). (Schwalbe, 2005)

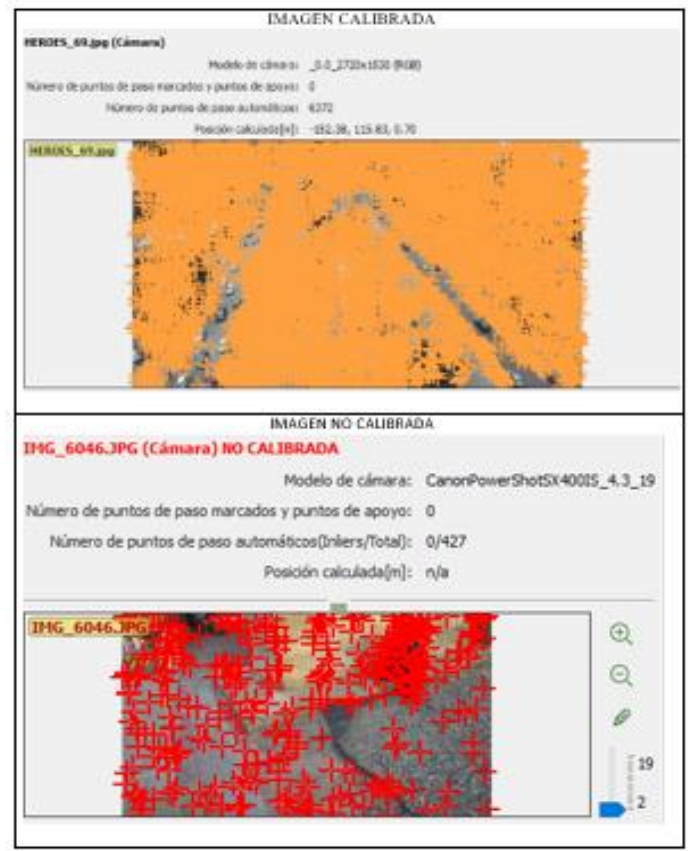

Figure 6: Calibration of the images to be used. Source: Own elaboration.

This calibration process analyzes sectors with less movement and or deformations not taking crossing points in these cases (car transit), and places where their movement of people.

This process is done to create the distribution of pass-through points that were uniformly reflected with good precision and execution in all processes by the logic in the detail of these (Figure 7).

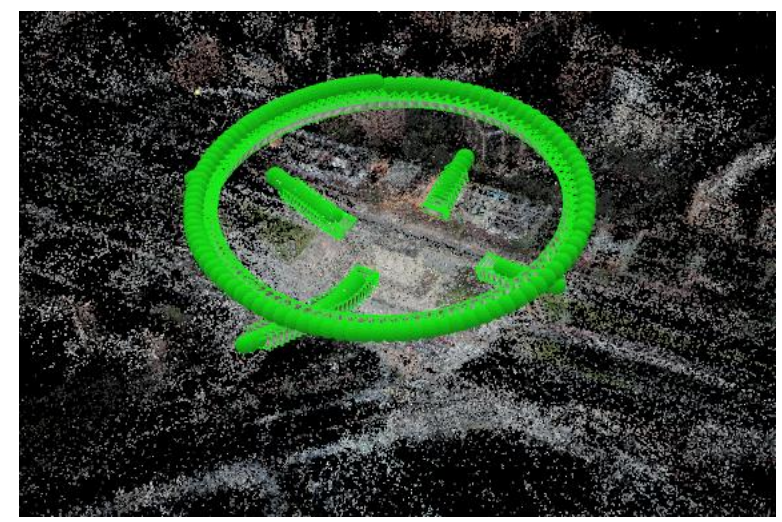

Figure 7: Distribution of the passage points of the Monument with processing with the frames generated by the drone tour. Source: Own elaboration.
From this data a cloud of points is created that represent the external surface of the monument, generating a data file with this cloud of points that were automatically taken by the program (Figure 8).

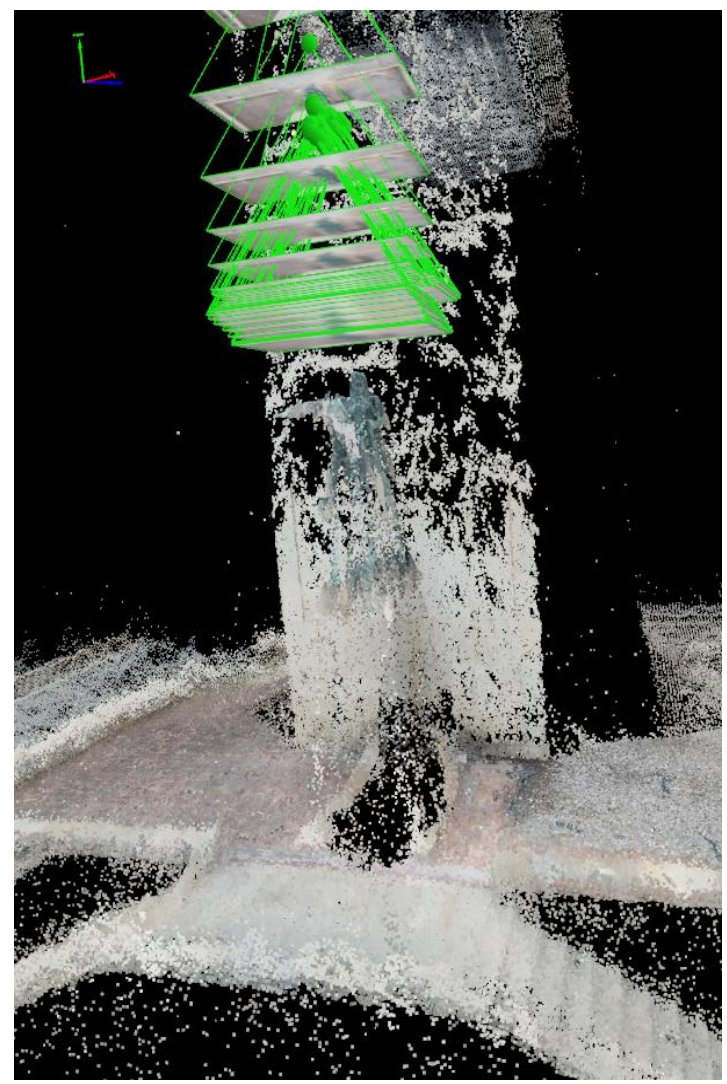

Figure 8: Monument points cloud with processing Photographs taken from a cenit-nadir view of the statue of Simon Equestrian Bolivar. Source: Own elaboration.

To finish it automatically generates a triangular mesh in which you can visualize the 3D reconstruction of the study area obtaining as a product a more detailed recognition of the object (Figure 9).

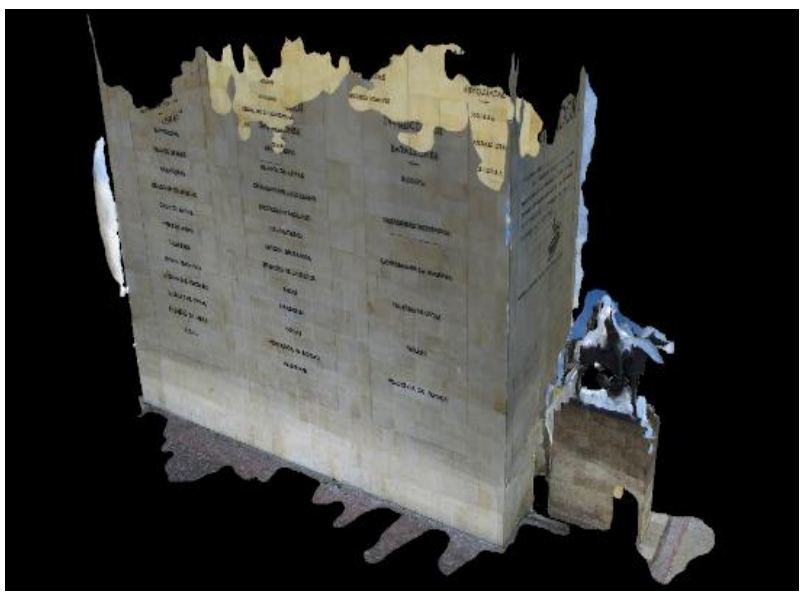

Figure 9: 3D Mesh of the Monument with the data capture processing generated by the CANON camera from the point of view of the earth's surface. Source: Own elaboration. 


\section{ANALYSIS AND RESULTS}

The results are generally satisfactory if you consider the ASPRS (American Society for Photogrammetry and Remote Sensing) geospatial data standards that require an error for this type of data especially for point cloud generation not greater than 1.5 times the pixel size and since the rebuild error in cases of a) 0.189235 , b) 0.223643 , c) 0.200842 , and d) 0.190172 and reflecting its good correlation between cameras (Figure 10); present good reliability for further developments using the reconstruction presented as a starting point.

In addition, by joining key point matches between images, they take dark tones that reflect the best correlation between them with respect to the location at the time of image capture and with light tones when there is not much of that image's match with respect to others, another aspect to look at is the average density per cubic meter is reflected that in option b) this data is lower compared to the others which means that its distortion in the final product is lower giving a better quality in the detail and structure of the monument to heroes; and in the sculpture of Simon Bolivar despite the lack of data its density is low representing on the surface where a good result is captured in the detail obtained. (Figure 10).

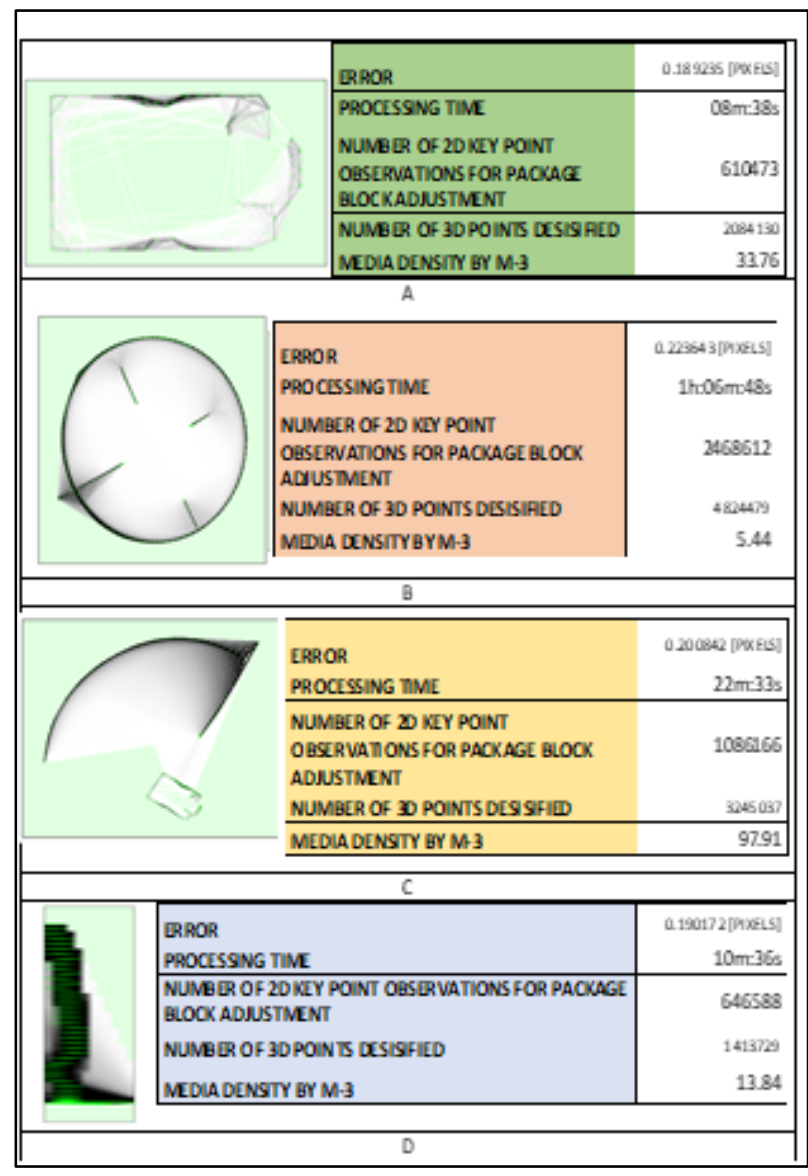

Figure 10: Two-dimensional correlation scheme for the processes performed.

Source: Own elaboration

It is evident that depending on the distribution of the images, the number of key points generated in the processing is deduced from the visualization of that point (Figure 11) in each image regardless of its inclination, scale and slight color change of the pixel, obtaining thus, in a few images, more points in common between them than in many images where only a lower consideration will be found in the similarity of that point in each of them; until the key points reach the point where there is no match between a large number of images and the reflection of it in all of them (Figure 12).

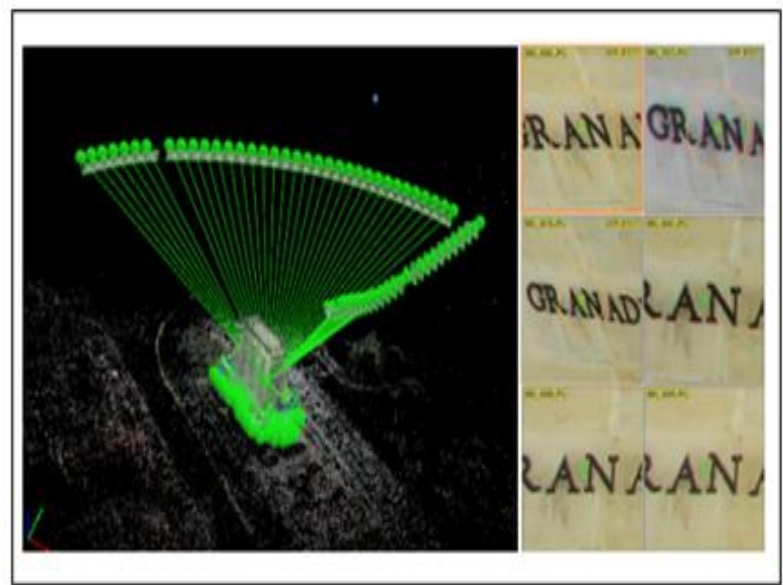

Figure 11: Displaying the same point between your different images in which the pixel appears. Source: Own elaboration

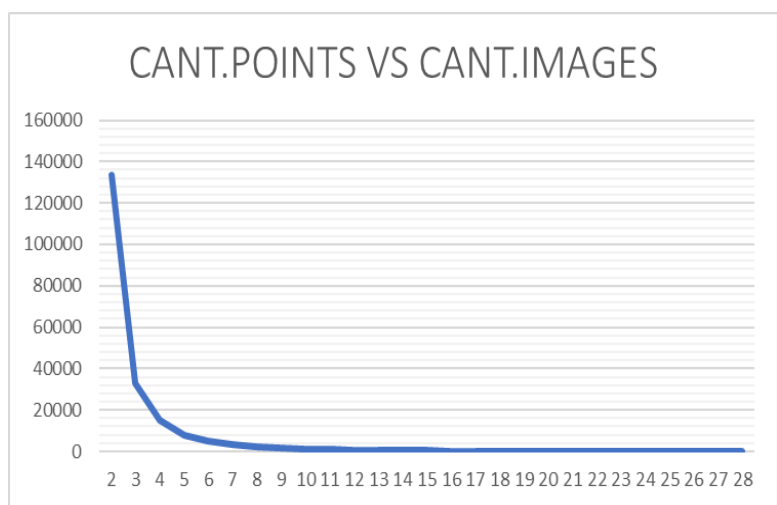

Figure 12: Display of common points vs images in which it appears.

Source: Own elaboration

\subsection{RECONSTRUCTION ANALYSIS PROCESSING A)}

In this process it is observed that when the images are captured from the surfaces the coating of the monument is not going to be completely complete, thus creating inconsistencies to me that the reconstruction began to take height creating deformations and alterations by cloudiness, establishing as common points existing clouds for the time the capture was taken (Figure 13); however it is evidenced a good detail in the lower parts of the monument showing good quality, object resolution.

In this process we can realize that the coincidence of points depends on the way in which this data was captured as the obtaining was from the surface is reflected that the quality of the final product was higher in the sector closest to the floor of the monument than in which the capture moves further away from the position and / or location of thecamera. (Figure 14). 


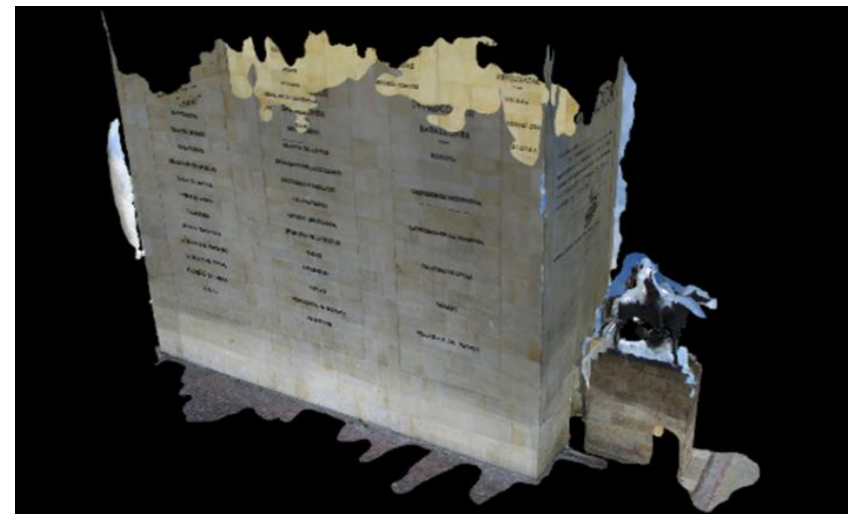

Figure 13: Result of $3 D$ reconstruction from capturing images from the full view surface.

Source: Own elaboration

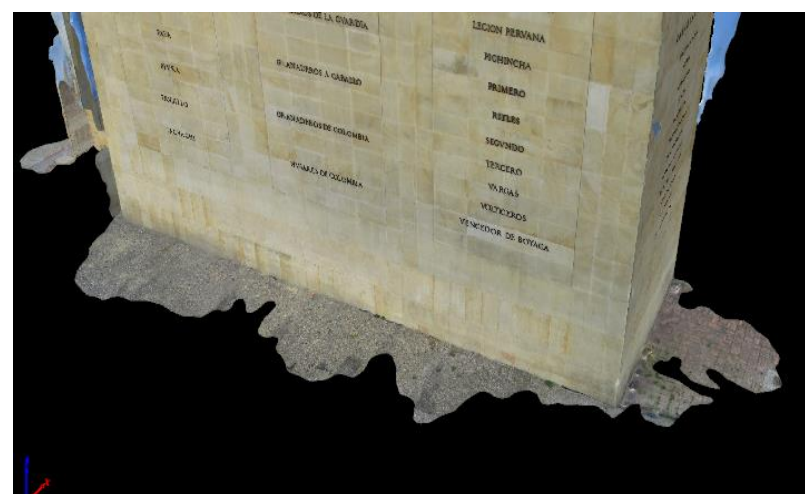

Figure 14: Result of $3 D$ reconstruction from capturing images from the surface bottom view of the monument. Source: Own elaboration

\subsection{RECONSTRUCTION ANALYSIS PROCESSING B)}

For the facades of the monument in this processing, the methodology developed from the use of the drone flight as soon as its analysis and quality verification yielded satisfactory results regarding shape, texture and low distortion given that the presenta a uniform and flat geometry the implementation the algorithm develops optimally in two dimensions, thus showing an excellent reconstruction in the structure related to its color, shape, dimension and texture although with deficiencies where the detail is greater (Figure 15).

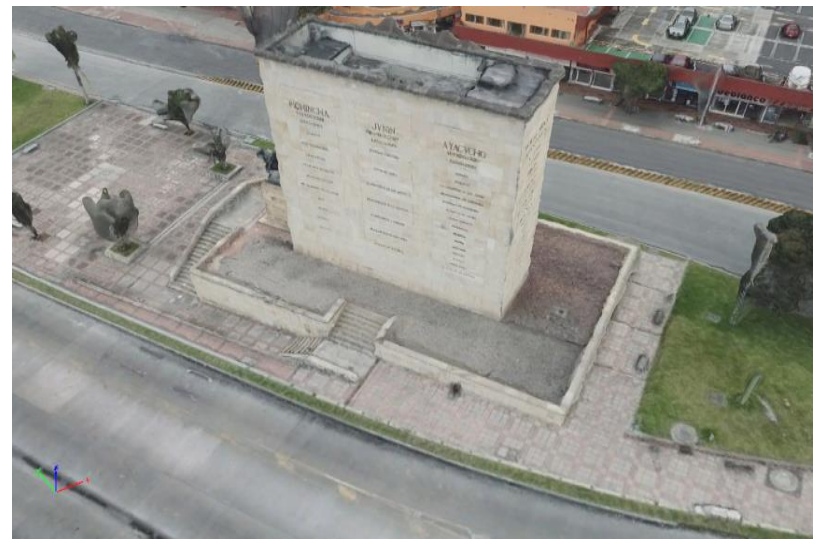

Figure 15: Result of $3 D$ reconstruction from capturing images from a top side view drone flight.

Source: Own elaboration

\subsection{RECONSTRUCTION ANALYSIS PROCESSING C)}

Although the previous two processes would yield a good result of the union of this data by its distance from the position of images of one process from the other I cause the redundancy of the data avoiding the calibration of the images finding irregularities for the final process and generating a very low correlation between these (Figure 16).

It can be shown that the data where the camera and drone are linked their result give detailed coherent and with good precision and quality while in what there was no union of these presents deformations in the general structure (Figure 17).

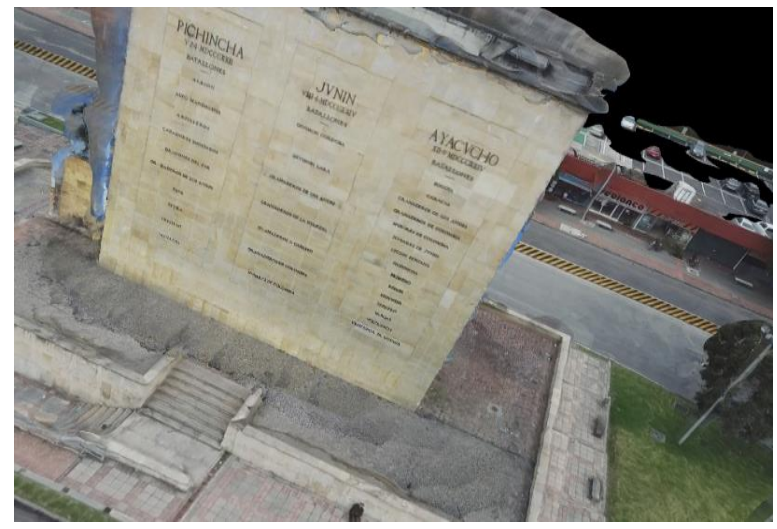

Figure 16: Result of $3 D$ reconstruction from capturing images from the surface and a drone flight. Source: Own elaboration

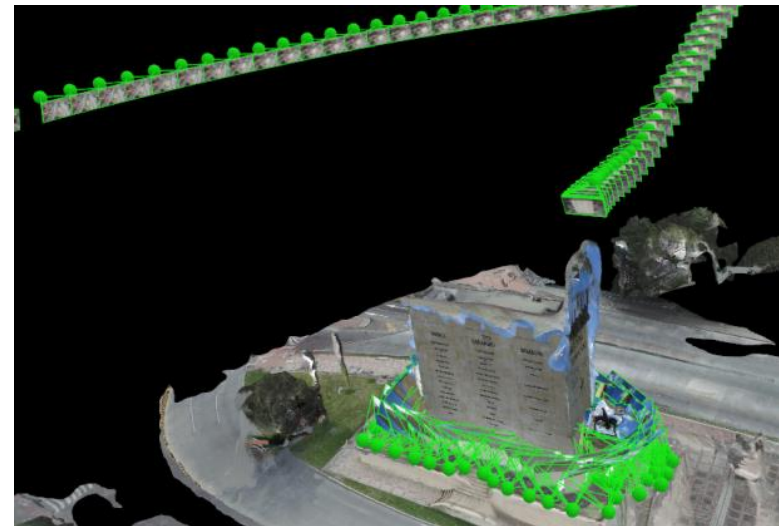

Figure 17: Result of $3 D$ reconstruction from capturing images from the surface and a flight of drone top side view of the sectors in which I miss captures of the drone flight. Source: Own elaboration

\subsection{RECONSTRUCTION ANALYSIS PROCESSING D)}

For the section of the equestrian Bolivar sculpture, the methodology applied using drones was not the best given that the level of detail is not as expected, although the shape, scale and color approached reality, given the conditions of implementation of the SIFT algorithm as a future work can be proposed a methodology and image capture in greater detail and closer (Figure 18).

It is therefore acceptable to see that where there was more capture it is possible to use this data obtaining good quality in detail with respect to the original structure. 


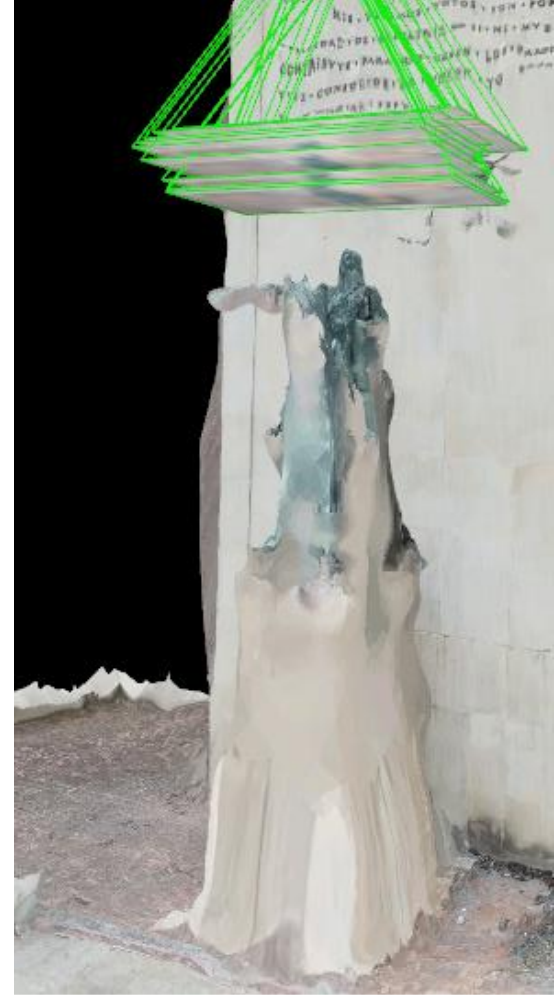

Figure 18: Result of the $3 D$ reconstruction of the sculpture of Equestrian Bolivar.

Source: Own elaboration

From the point of view where the shots are seen from zenith to nadir the result obtained shows a great detail in the sculpture, creating excellent quality in its texture and color of the final object (Figure 19).

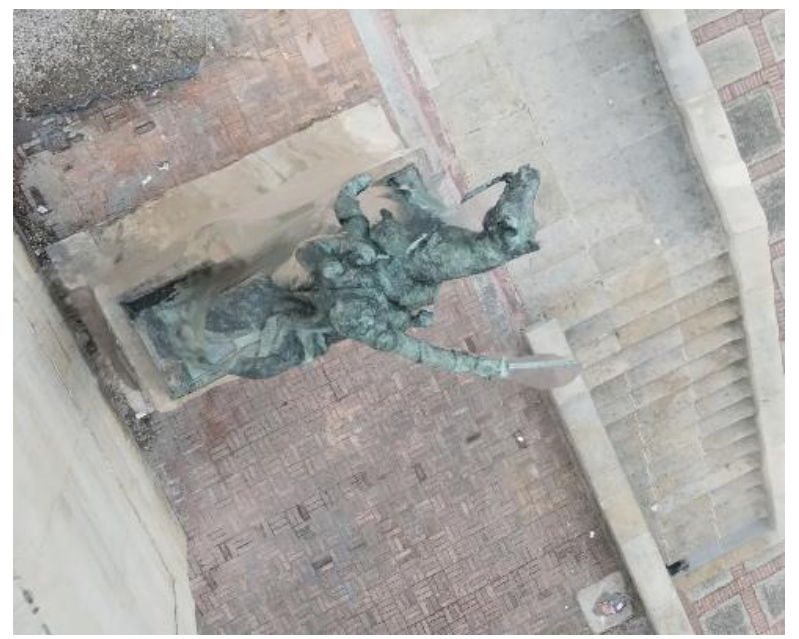

Figure 19: Result of the $3 D$ reconstruction of the sculpture of Equestrian Bolivar.

Source: Own elaboration

\section{FUTURE APPROACH:}

As a final goal you want to Insert that model to Google Earth (Google Sketchup) for Georeferencing, Web Modeling and monument documentation with the intention of appropriation and patrimonization within the framework of the monument adoption program carried out by the District Institute of Cultural Heritage - IDPC. (Forero \& Alberto, 2018)
Transforming from a two-dimensional flat image (Image 20) to a three-dimensional image (Image 21).

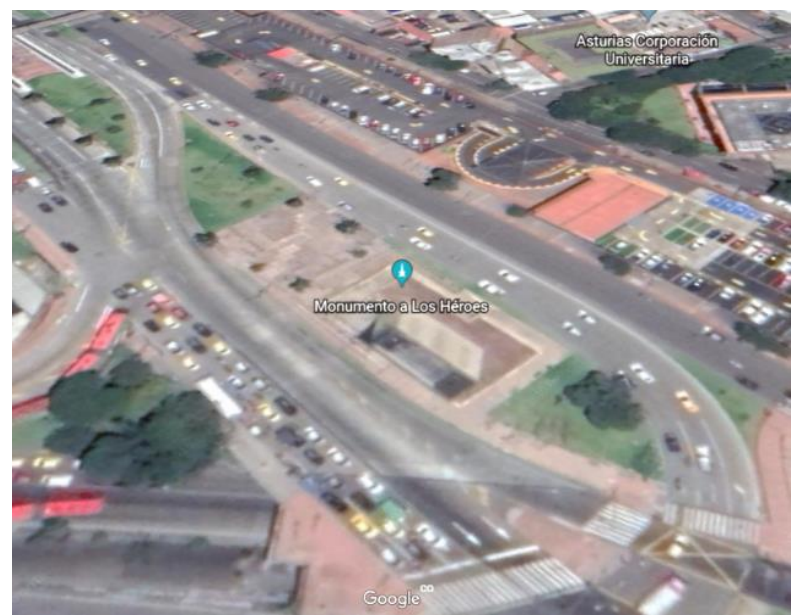

Figure 18: Overview of the Heroes Monument on Google Earth. Source: Google Sketchup

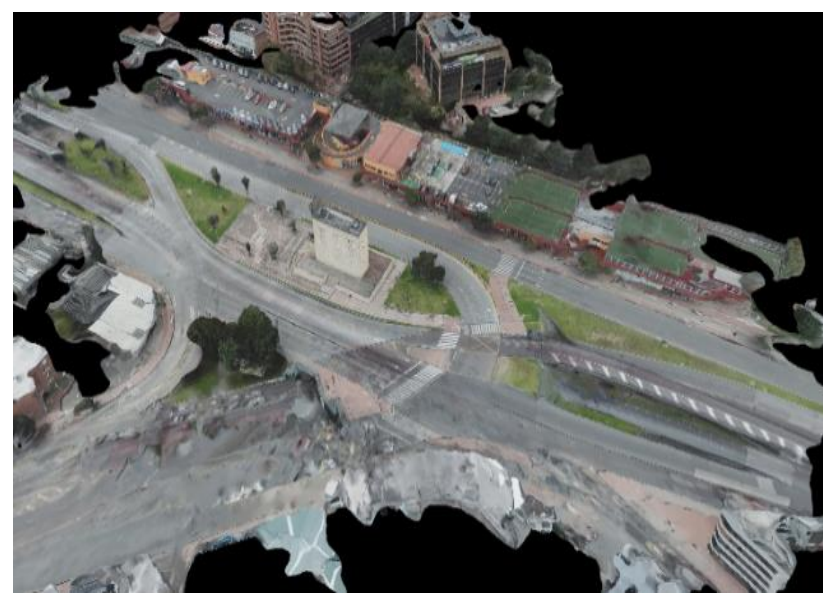

Figure 18: Overview of $3 D$ Reconstruction of the Monument toHeroes.

Source: Google Sketchup

\section{CONCLUSIONS}

The objective is achieved by choosing the process taken by the drone because, having importance as a monument and its possible demolition condition, its construction characteristics typical of the facade and its state of conservation can be the starting point for the reconstruction where you want to move, for the quality, the low error, the low distortion, texture and homogeneous colors according to the current conditions of the monument.

From this it can be said that the use of 3D modeling beyond being visually appealing and giving way to what is known as virtual reality can be used in different disciplines, to give a real view of the environment in which we find ourselves, this being an innovative methodology in the processes that have been made in Colombia so these apeas technologies have been implemented in the country. Obtaining for this process a methodology with a level of detail in terms of aspects in the form, texture and composition very acceptable because the data collection was the most appropriate with respect to the structure instead with regarding the sculpture of Simón Bolívar equestrian the results were not the most optimal, in this case for later processes it is recommended to make closer captures to define in more detail the sculpture. (Noguera Giménez, 2002) 


\section{ACKNOWLENDGMENTS}

I thank Professor Erika Upegui because with her help and collaboration in guidance during the process regarding the development and management of the program, a very good final result could be obtained.

Finally, to the Instituto Distrital De Patrimonio Cultural - IDPC for the information provided on the drone flight from its videos generated to obtain frames.

\section{References}

Abad García, C. 2017: Estudio de técnica de generación de modelos 3D a partir de secuencias de imágenes. Recuperado de https://repositorio.unican.es/xmlui/handle/10902/11974

Barazzetti, L., Previtali, M., \& Roncoroni, F. 2017: Fisheye lenses for $3 \mathrm{~d}$ modeling: evaluations and considerations. ISPRS International Archives of the Photogrammetry, Remote Sensing and Spatial Information Sciences, XLII-2/W3, 79-84. https://doi.org/10.5194/isprs-archives-XLII-2-W3-79-2017

Forero, P., \& Alberto, F. 2018: Ficha Técnica para la Valoración de Inmuebles de Conservación Arquitectónica. Recuperado de http://repository.udistrital.edu.co/handle/11349/7771

García, J. L. P., Calvache, A. T. M., Escarcena, F. J. C., \& Arenas, A. L. 2011: Fotogrametría de bajo coste para la modelización de edificios históricos. Virtual Archaeology Review, 2(3), 121-125. https://doi.org/10.4995/var.2011.4633

Gutiérrez Gómez, V. 2018: La inserción del Patrimonio en los estudios universitarios. Recuperado de http://dspace.uclv.edu.cu:8089/xmlui/handle/123456789/10583

IDPC. 2016, julio 12: Así comenzó IndieBox en Los Héroes. Recuperado 7 de septiembre de 2019, de Instituto Distrital De Patrimonio Cultural website: https://idpc.gov.co/asi-comenzoindibox-los-heroes/

Kumar, R., Muknahallipatna, S., \& McInroy, J. 2016: An Approach to Parallelization of SIFT Algorithm on GPUs for Real-Time Applications. Journal of Computer and Communications, 04, 18-50. https://doi.org/10.4236/jcc.2016.417002
Noguera Giménez, J. F. 2002: La conservación activa del patrimonio arquitectónico. Loggia, Arquitectura \& Restauración, (13), 10. https://doi.org/10.4995/loggia.2002.3569

Pérez, J. A., Gonçalves, G. R., Rangel, J. M. G., \& Ortega, P. F. 2019: Accuracy and effectiveness of orthophotos obtained from low cost UASs video imagery for traffic accident scenes documentation. Advances in Engineering Software, 132, 47-54. https://doi.org/10.1016/j.advengsoft.2019.03.010

Schneider, D., Schwalbe, E., \& Maas, H.-G. 2009: Validation of geometric models for fisheye lenses. ISPRS Journal of Photogrammetry and Remote Sensing, 64(3), 259-266. https://doi.org/10.1016/j.isprsjprs.2009.01.001

Schwalbe, E. 2005: Geometric modelling and calibration of fisheye lens camera systems.

Strecha, C., Zoller, R., Rutishauser, S., Brot, B., Zapp, K. C., Chovancova, V., ... Glassey, L. M. 2015: Terrestrial 3d Mapping Using Fisheye and Perspective Sensors.

Tiempo, C. E. E. 2016, julio 12: Alcaldía invita a conocer el renovado monumento de Los Héroes. Recuperado 11 de septiembre de 2019, de El Tiempo website: https://www.eltiempo.com/archivo/documento/CMS-16643453

Vinuesa, M. Á. T. (1998). Patrimonio arquitectónico, cultura y territorio. Ciudades: Revista del Instituto Universitario de Urbanística de la Universidad de Valladolid, (4), 95-104. 